\title{
AN ANALYSIS ON DISTANCE EDUCATION COMPUTER PROGRAMMING STUDENTS' ATTITUDES REGARDING PROGRAMMING AND THEIR SELF-EFFICACY FOR PROGRAMMING
}

\author{
Assist. Prof. Dr. Ozcan OZYURT \\ Karadeniz Technical University, \\ Technology Faculty, \\ Software Engineering Department, \\ Trabzon, TURKEY
}

\begin{abstract}
This study aims to analyze the attitudes of students studying computer programming through the distance education regarding programming, and their self-efficacy for programming and the relation between these two factors. The study is conducted with 104 students being thought with distance education in a university in the north region of Turkey in spring semester of 2013-2014 academic years. Attitude Scale toward Computer Programming (AStCP) and Computer Programming Self-Efficacy Inventory (CPSEI) are used as data collecting tool. The study is conducted within the descriptive scanning model. The data collected during the study is analyzed with Mann Whitney $U$ test, independent t-test and Pearson Correlation coefficient for answering the research questions. According to the results of the study the attitudes of the students regarding programming are generally positive and their self-efficacy for programming are at high level. There is statistically important difference in the attitudes of students regarding programming in accordance with their gender and grade level. Accordingly, their selfefficacy differentiates statistically by these two variables. Finally, it is concluded that there is a positive relation in average level between the attitudes of the students regarding programming and their self-efficacy for programming.
\end{abstract}

Keywords: Attitudes Regarding Programming, Programming Self-Efficacy, Distance Education, Computer Programming.

\section{INTRODUCTION}

Computer programming is one of the most popular occupations in these days. There is Computer Programming Program under the Computer Technologies Department in the vocational high school of almost all the universities. These programs firstly have been founded as formal and evening education and they have continued their education and teaching activities. In recent years, in parallel with the developments in distance education technologies, distance education computer programming program has been opened in several universities and they still continue their activities. The main objective of computer programming programs is to prepare programmers having the technical knowledge and experience to be able to use information technologies and accommodate with the improving technologies. It is expected from the computer programming candidates to be graduated from this program to have computer programming skill at 
upper level.Computer programming skill requires having some kind of thinking skill such as logical thinking and problem solving (Korkmaz, 2012; Lau \& Yuen, 2009).

Computer programming is mostly perceived as a difficult course by the students (Aşkar \& Davenport, 2009; Başer, 2013).

The fact that computer programming is perceived as a difficult course results in the fact that they develop mostly negative attitudes regarding programming (Başer, 2013). Negative attitude regarding programming has a negative effect on the success of students. Hence, the studies finding out that such factors as negative perception, motivation and especially low level of attitude can make negative effect on learning computer programming take the attention (Anastasiadou \& Karakos, 2011; Hawi, 2010; Korkmaz \& Altun, 2013).

It can be said that beside attitude, self-efficacy perception also plays a role in success of the students in computer programming course. Self-efficacy refers to the trust on the skill that the individual has in order to be able perform a work (Horzum \& Çakır, 2009).

It is possible to encounter with the studies indicating the fact that it is highly possible that the student whose self-efficacy trust is lower will be unsuccessful in programming course (Altun \& Mazman, 2012; Aşkar \& Davenport, 2009). And the literature also includes information about there is a positive relation between attitude and self-efficacy (Demirtaş, Cömert, \& Özer, 2011).

There are studies in very limited number in literature about the attitude regarding programming and programming self-efficacy trust. Hongwarittorrn and Krairit (2010) reach the result that there is an important correlation between the attitudes regarding programming and the exam marks. There are generally studies concluding that the attitudes of students regarding programming are positive (Anastasiadou \& Karakos, 2011; Başer, 2013; Korkmaz \& Altun, 2013; Nurazian, Suzana, Haslızatul, \& Isamassabah, 2007). Furthermore, although there are studies concluding that the attitudes of male students are higher than the female students' (Başer, 2013; Chang, Shieh, Liu, \& Yu, 2012; Stoilescu, \& Egodawatte, 2010), there are also studies finding out that there is no relation between the attitude regarding programming and gender (Lau \& Yuen, 2009; McDowell, Werner, Bullock, \& Fernald, 2003).

There are very limited studies about the self-efficacy perception for programming. According to Aşkar and Davenport (2009) self-efficacy perception for programming shows important differences by gender and departments, male and computer engineering students' self-efficacy perception for programming are at higher level in comparison with other students.

According to Jegede (2009) the number of the courses taken in previous times and the year end mark gotten from these courses determine the self-efficacy for programming, but experience year for programming has no effect. Altun and Mazman (2012), find out that programming self-efficacy perception does not vary by gender; on the other hand it varies by the courses about programming and programming experience year.

Furthermore, literature also includes the studies concluding that the self-efficacy perception of the students for programming are at average level (Pereira, Zebende, \& Moret, 2010; Hawi, 2010; Robins, Rountree, \& Rountree, 2003). 
It is seen that existing studies about the attitude regarding programming and selfefficacy density in engineering and computer education department. There are studies about student satisfaction of the students generally from the different departments, in specific students from computer programming who take education via distance education (Allen, Bourhis, Burrell, \& Mabry, 2002; Ozyurt, 2014), and the attitudes of the students regarding their department and/or distance education (Lenka \& Kant, 2012; Ojo \& Olakulehin, 2006; Ozyurt, 2014; Ural, 2007) in literature. There is not any study searching the attitudes of the students studying at Distance Education Computer Programming Program regarding programming and their thrust on self-efficacy. However, in our day, many universities give the computer programming education through the distance education. In this context this study aims to inspect the attitudes of the computer programming candidates taking education through distance education regarding programming and their trust on programming self-sufficiency. It is thought that the study, by its content and scope, will fill an important gap in literature and make a contribution to computer programming education made through distance education.

\section{METHODOLOGY}

\section{Aim and Research Questions}

This study aims to search the attitudes of computer programming candidates taking education via distance education, their self-efficacy for programming and the relation between them. The research questions of the study can be listed as:

$>$ What is the level of the attitudes of the distance education computer programming students regarding programming in general and on the basis of sub-factors?

- Do the attitudes of these students regarding programming differentiate by gender both generally and on the basis of subfactors?

- Do the attitudes of these students regarding programming differentiate by class level both generally and on the basis of sub-factors?

$>$ What is the level of the programming self-efficacy of the distance education computer programming students both generally and on the basis of sub-factors?

- Does the programming self-efficacy of these students differentiate by gender both generally and on the basis of subfactors?

- Does the programming self-efficacy of these students differentiate by class level both generally and on the basis of sub-factors?

$>$ Is there any relation between the attitudes of these students regarding programming and their programming self-efficacy?

- Is there any relation between attitudes of these students regarding programming and their programming self-efficacy by gender?

- Is there any relation between the attitudes of these students regarding programming and their programming self-efficacy by class level?

Sample

The Sample of this study consists of 104 students studying at Distance Education Computer Programming Program in vocational school of higher education in a university 
in the north region of Turkey. The distribution of the participants by their gender is as male $(n=87, f=83.7 \%)$ and female $(n=17, f=16.3 \%)$, and their distribution by grade level is as 1. grade $(n=49, f=47.1 \%)$ and 2 . grade $(n=55, f=52.9 \%)$. This study has been conducted in 2013-2014 academic year, spring semester.

\section{Data Collection Tool}

In this study, Attitude Scale toward Computer Programming (AStCP) and Computer Programming Self-Efficacy Inventory (CPSEI) is used as data collection tool. AStCP is designed by Başer (2013). AStCP consists of 38 items and it is designed as 5-point Likert scale as to give answer to the choices such as "strongly disagree", "disagree", "undecided", "agree" and "strongly agree". Answers given to the each item by the students are listed as a numerical value as 1-5. AStCP consists of four factors named as "F1: Self-confidence and motivation in programming", "F2: Benefit of programming", "F3: Attitude regarding success in programming", "F4: Social perception of success in programming". Validity and reliability examination of the scale is conducted by the researcher (Başer, 2013) and Cronbach-a reliability coefficient is found out as 0.953 .

CPSEI is designed by Altun and Mazman (2012). CPSEI consists of 9 items and it is designed as 7-point Likert scale as to give answer to the choices such as "I never feel confident", "I do not feel confident generally", "I feel confident a little bit", "\%50 \%50", "I feel rather confident", "I feel confident generally", "I feel confident totally". Answers given to the each item by the students are listed as a numerical value as 1-7. CPSEI consists of 2 items named as "F1: Fulfilling basic programming tasks" and "F2: Fulfilling complex programming tasks". Validity and reliability examination of the scale is conducted by the researcher (Altun \& Mazman, 2012) and Cronbach-a reliability coefficient is found out as 0.928 .

\section{Data Analysis}

According to Yenilmez (2008) point intervals in 5-point Likert scales can be categorized as in order to increase the statistical comprehensibility as to give answer to the choices such as "strongly disagree (1.0-1.80)", "disagree (1.81-2.60)", "undecided (2.61-3.40)", "agree (3.41-4.20)" and "strongly agree (4.21-5.0)". In accordance with this statement, points intervals of AStCP having 5-point Likert type are graded as "strongly disagree: 1.01.80"; "disagree: 1.81-2.60"; "undecided: 2.61-3.40"; "agree: 3.41-4.20" and "strongly agree: 4.21-5.0". Accordingly point intervals of CPSEI having 7-point Likert type are graded as "I never feel confident: 1.0-1.86"; "I do not feel confident generally: 1.872.72"; "I feel confident a little bit: 2.73-3.58"; "\%50 \%50: 3.59-4.44"; "I feel rather confident: 4.45-5.30"; "I generally feel confident: 5.31-6.16", and "I totally feel confident: 6.17-7.0".

The research has been conducted out with the descriptive scanning model. Attitudes of the distance education computer programming students regarding the programming and the level of their programming self-efficacy are determined by calculating the average point. Because of the fact that the distribution of the data do not show normal parameters according to the groups, whether attitude regarding the programming and the level of programming self-efficacy differentiate by gender is searched with Mann Whitney U-test one of the non-parametric tests.

Whether attitude regarding the programming and the level of programming self-efficacy differentiate by class level is searched with independent t-test one of the parametric tests for the data which range normally from group to group and the data which do not range normally from group to group is searched with Mann Whitney U-test which is one of the non-parametric tests. Finally, the relation between the attitude regarding programming 
and programming self-efficacy is searched with Pearson Correlation coefficient. This calculation is repeated by taking into consideration the gender and class level. If the correlation coefficient is $\mathbf{1 . 0 0}$, this refers to perfect positive relation, if it is $\mathbf{- 1 . 0 0}$ on the other hand; this refers to perfect negative relation. If the correlation coefficient is between $0.70-1.00$ as an absolute value it refers a relation at high level, if it is between $0.70-0.30$ this refers average relation and if it is between $0.30-0.00$, this refers a relation at low level (Büyüköztürk, 2007). The data have been analyzed with SPSS 16.0 pocket program.

\section{FINDINGS}

Findings obtained from the study are presented in accordance with the research questions.

\section{Findings about the Attitudes of the Distance Education}

Computer Programming Students Regarding Programming

The average of the point that the distance education computer programming students get from the AStCP is 3.81. This average point is seen in the interval of "Agree". Relying on this the attitudes of students regarding the programming can be evaluated as positive. Table 1 shows the result of Mann Whitney U-test showing whether the points of the students' attitudes regarding the programming differentiate or not by gender both generally and on the basis of sub-factors.

Table: 1

Result of Mann Whitney U-test showing whether the points of the distance education computer programming students' attitudes regarding the programming differentiate or not by gender both generally and on the basis of factors.

\begin{tabular}{|c|c|c|c|c|c|c|}
\hline & Group & $\mathbf{N}$ & Mean Rank & Sum of Ranks & $\mathbf{U}$ & $\mathbf{p}$ \\
\hline & Female & 17 & 34.65 & 589 & 436 & .007 \\
\hline & Male & 87 & 55.99 & 4871 & & \\
\hline \multirow{2}{*}{ Factor 1} & Female & 17 & 52.15 & 886.5 & 554.5 & .103 \\
\hline & Male & 87 & 52.57 & 4573.5 & & \\
\hline \multirow{2}{*}{ Factor 2} & Female & 17 & 38.79 & 659.5 & 733.5 & .958 \\
\hline & Male & 87 & 55.18 & 4800.5 & & \\
\hline \multirow{2}{*}{ Factor 3} & Female & 17 & 44.94 & 764 & 506.5 & .040 \\
\hline & Male & 87 & 53.98 & 4696 & & \\
\hline \multirow{2}{*}{ Factor 4} & Female & 17 & 37.88 & 644 & 611 & .250 \\
\hline & Male & 87 & 55.36 & 4816 & & \\
\hline
\end{tabular}

When the Table: 1 is analyzed, it is seen that the attitude regarding the programming show differences by gender statistically $(U=436, p<0.05)$.

When the grade averages of the groups are taken into consideration, it is seen that male students have higher attitude regarding the programming than female students. When it is analyzed on the basis of sub-factors, there is not any statistical difference at the first, second and fourth factors, on the other hand, at the third factor (F3: Social perception of success in programming) it is seen that there is a statistical difference in the favor of male students $(U=764, p<0.05)$. Findings about whether the attitudes of the students 
regarding the programming differentiate statistically by grade level are presented in Table: 2.

Table: 2

The result of independent $t$-test showing whether the attitudes of the distance education computer programming students regarding the programming differentiate statistically by grade level

\begin{tabular}{ccccccc}
\hline Group & N & $\bar{X}$ & Sd & df & t & p \\
\hline Grade 1 & 49 & 3.73 & 0.437 & 102 & 2.093 & .039 \\
Grade 2 & 55 & 3.88 & 0.306 & & & \\
\hline p $<.05$ & & & & & &
\end{tabular}

When the Table 2 is analyzed, it is seen that, attitudes of the students regarding the programming differentiate statistically by grade level [t $(102)=2.093, p<.05]$. The attitudes $(\bar{X}=3.88)$ of the students in second grade level regarding the programming are more positive than the ones in first grade level $(\bar{X}=3.73)$. The results of Mann Whitney Utest and Independent $t$-test showing that whether the attitudes of the distance education computer programming students regarding the programming differentiate by grade level on the basis of sub-factors are given in Table 3 and 4.

Table: 3

Mann Whitney U-test showing that whether attitudes of the distance education computer programming students regarding the programming differentiate by grade level on the basis of first sub-factor.

\begin{tabular}{ccccccc}
\hline & Group & N & Mean Rank & Sum of Ranks & U & p \\
\multirow{2}{*}{ Factor 1 } & Grade 1 & 49 & 42.02 & 2059 & 834 & .001 \\
& Grade 2 & 55 & 61.84 & 3401 & & \\
\hline \multicolumn{2}{c}{$\mathrm{p}<.05$} & & & &
\end{tabular}

Table: 4

The result of independent t-test showing that whether attitudes of the distance education computer programming students regarding the programming differentiate by grade level on the basis of second, third and fourth sub-factor.

\begin{tabular}{clllllll}
\hline & Group & N & $\bar{X}$ & Sd & df & t & p \\
\hline \multirow{2}{*}{ Factor 2 } & Grade 1 & 49 & 3.679 & .432 & 102 & 0.436 & .664 \\
& Grade 2 & 55 & 3.645 & .366 & & & \\
\hline \multirow{2}{*}{ Factor 3 } & Grade 1 & 49 & 3.964 & .776 & 102 & 0.096 & .924 \\
& Grade 2 & 55 & 3.977 & .602 & & & \\
\hline \multirow{2}{*}{ Factor 4 } & Grade 1 & 49 & 4.183 & .670 & 102 & \multirow{10}{*}{1.319} & .190 \\
& Grade 2 & 55 & 3.987 & .823 & & & \\
\hline p<.05 & & & & & &
\end{tabular}

When the Table 3 and Table 4 are interpreted, it is seen that in the first factor "F1: Selfconfidence and motivation in programming", there is an important statistical difference in the favor of the students in second grade $(U=834, p<.05)$, however there is not any important statistical difference by grade level in other factors $[t(102)=0.436, p>.05$, $t(102)=0.096, p>.05, t(102)=1.319, p>.05]$. 


\section{Findings about the Programming Self-Efficacy}

\section{of the Distance Education Computer Programming Students}

The average of the point that distance education computer programming students get in CPSEI is 5.0. This average point is seen in the interval of" I feel rather confident". According to this finding, the programming self-efficacy of the students can be regarded as positive/high. In Table 5, the result of Mann Whitney U-test showing whether the programming of self-efficacy of the students differentiate by gender both generally and on the basis of sub factors is given.

Table: 5

The result of Mann Whitney U-test showing whether the programming self-efficacy of the distance education computer programming students differentiate by gender

\begin{tabular}{ccccccc}
\hline & Group & N & Mean Rank & Sum of Ranks & U & p \\
\hline & Female & 17 & 37.88 & 644 & 491 & .029 \\
& Male & 87 & 55.36 & 4816 & & \\
\hline \multirow{2}{*}{ Factor 1 } & Female & 17 & 38.76 & 659 & 506 & .033 \\
& Male & 87 & 55.18 & 4801 & & \\
\hline \multirow{2}{*}{ Factor 2 } & Female & 17 & 43.21 & 734.5 & 581.5 & .163 \\
\hline p<.05 & Male & 87 & 54.32 & 4725.5 & & \\
\hline
\end{tabular}

When the Table 5 is analyzed, it is seen that programming self-efficacy statistically differentiate by gender $(\mathrm{U}=491, \mathrm{p}<0.05)$. When the grade average is taken into consideration, it is seen that the programming self-efficacy of the male students are higher that the female students. In terms of sub factors, it is seen that male students have higher self-efficacy than female students for "F1: Basic programming task" (U=506, $p<0.05$ ). The findings about whether programming self-efficacy of the students differentiate statistically by grade level are given in Table 6.

Table: 6

The result of independent $t$-test showing whether the programming self-efficacy of the distance education computer programming students differentiate by grade level

\begin{tabular}{|c|c|c|c|c|c|c|c|}
\hline & Group & $\mathbf{N}$ & $\overline{\boldsymbol{X}}$ & Sd & df & $\mathbf{t}$ & p \\
\hline & Grade 1 & 49 & 4.24 & 1.30433 & 102 & 5.662 & .000 \\
\hline & Grade 2 & 55 & 5.68 & 1.28225 & & & \\
\hline \multirow{2}{*}{ Factor 1} & Grade 1 & 49 & 4.7143 & 1.52297 & 102 & 0.096 & .000 \\
\hline & Grade 2 & 55 & 6.3212 & 1.33790 & & & \\
\hline \multirow{2}{*}{ Factor 2} & Grade 1 & 49 & 4.0136 & 1.52671 & 102 & 2.039 & .000 \\
\hline & Grade 2 & 55 & 5.3667 & 1.40999 & & & \\
\hline
\end{tabular}

According to the findings in Table 6, programming self-efficacy of the students do not differentiate statistically by grade level $[t(102)=5.662, p<.05]$. When the average points are taken into consideration, it is seen that the self-efficacy of the 2nd grade students $(\bar{X}=5.68)$ are higher than 1st grade students $(\bar{X}=4.24)$. On the basis of sub-factors, when both factors are interpreted by grade level, a statistically important difference is seen in the favor of 2 nd grade students $[t(102)=0.096, p<.05, t(102)=2.039, p<.05]$. 
Findings about the Relation between the Attitudes of the Distance Education Computer Programming

Students Regarding the Programming and Their Self-Efficacy Level

It is concluded that, there is a positive, important and moderate relation between the attitudes of the distance education computer programming students regarding the programming and their self-efficacy level $(r=0.516, p<.01)$. The findings show that there is an important relation between the attitudes of the students regarding the programming and their self-efficacy level by gender and grade level. While there is a strong and important relation between the attitudes of female students regarding the programming and their self-efficacy $(r=0.845, p<.01)$, it is seen that this relation is positive and moderate among the male students $(r=0.464, p<.01)$. Furthermore, there is an important positive and moderate relation between the attitudes of the 1st and 2nd grade students regarding the programming and their programming self-efficacy $(r=0.647$, $\mathrm{p}<.01 ; \mathrm{r}=0.300, \mathrm{p}<0.01$ respectively).

\section{CONCLUSIONS and DISCUSSIONS}

This study deals with the attitudes of the students studying computer programming through distance education regarding programming and their programming self-efficacy and the relation between them and the results are analyzed and discussed. According to the results obtained from the study, the attitudes of the distance education computer programming students regarding programming are generally positive. The attitudes of the students regarding programming differentiate by gender statistically in favor of male students. When the results are analyzed on the basis of sub factors, it is seen that while there is an important difference in the factor "Social perception of success in programming" in the favor of male students, there is not any important difference in other three factors by gender. When the influence of grade level on the attitude regarding programming is searched, it is concluded that there is a statistically important difference in the favor of 2 nd grade students.

In terms of sub-factors, while there is a statistically important difference in "Selfconfident and motivation in programming" factor in favor of 2 nd grade students, in other three factors, there is not any important difference by grade level. The results of this study have parallels with studies in the literature which reach the result that the attitudes of students regarding programming are positive Anastasiadou \& Karakos, 2011; Başer, 2013; Korkmaz \& Altun, 2013; Nurazian, et al., 2007).

Additionally, beside the studies concluding that gender has no influence on the attitude regarding programming (Lau \& Yuen, 2009; McDowell, et al., 2003), there are also studies concluding that male students have more positive attitude regarding programming than female students (Başer, 2013; Chang, et al., 2012; Stoilescu, \& Egodawatte, 2010). The result of this study supports the studies concluding that gender affects the attitude regarding programming.

According to the results about self-efficacy, it is seen that the computer programming self-efficacy of the students are generally high. It is concluded that programming selfefficacy of the students have statistically important differences in accordance with gender and grade level similar to their attitude points. Hence, in terms of gender, there is important difference in programming self-efficacy of the students in the favor of male students. On the basis of sub-factors, there is a difference in "basic programming tasks" factor in favor of male students, but there is not any important difference in other factors by gender. In terms of the influence of grade level on programming self-efficacy, it is seen that there is a statistically important difference in favor of 2 nd grade students both 
generally and on the basis of sub-factors. Programming self-efficacy of the students is at average level in many studies in the literature (Pereira, et al., 2010; Hawi, 2010; Robins, et al., 2003); however, it is at high level in this study. The result of the study differs from the literature with this point. The fact that students chose computer programming as an occupation may have an active role in the result that their self-efficacy is high. Beside the studies trying to reach the result that gender has no influence on programming selfefficacy (Altun \& Mazman, 2012), there are also studies concluding that gender has an influence on self-efficacy (Aşkar \& Davenport, 2009) in literature. The results of the study support the study of Akşar and Davenport (2009) on that sense. The fact that programming self-efficacy varies by grade level supports the result that number of the courses taken about programming and the year of experience in programming affect the self-efficacy which is included in literature (Aşkar \& Davenport 2009; Jegede, 2009).

Finally, it is concluded that there is a statistically important relation in a positive direction and at average level between the attitudes of the students regarding programming and their programming self-efficacy. If the relation between the attitude regarding the programming and programming self-efficacy is analyzed in terms of gender, while this relation is positive and strong for the female students, it is positive and at average strength for the male students. In terms of grade level, it is concluded that this relation is positive and at average strength for 1st and 2 nd grade students. The results obtained from the study, become more comprehensible when the attitude regarding programming and programming self-efficacy are considered together. Hence, both the attitude regarding programming and programming self-efficacy varies statistically by gender and class level. This differentiation is at the same direction for both variables. The fact that there is a relation in positive direction and average level between the attitude and selfefficacy makes these results meaningful. Thus, the attitude of an individual whose selfefficacy is high is also expected to be high, and similarly, the self-efficacy of an individual whose attitude is high is expected to be high.

\section{BIODATA and CONTACT ADDRESSES of AUTHOR}

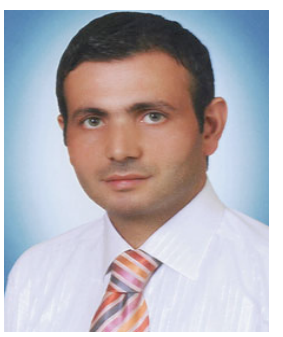

Ozcan OZYURT was born in Trabzon, Turkey in 1978. He received the B.Sc. and M.Sc. degrees in Computer Engineering from Karadeniz Technical University (KTU) in 1996 and 2000, respectively. He completed his doctoral studies (Ph.D.) on adaptive and educational hypermedia in secondary mathematics education at Karadeniz Technical University, 2013. Now, he has been working as a full-time faculty member, Assist. Prof. Dr., in the Software Engineering Department, OF Technology Faculty, Karadeniz Technical University, Trabzon, Turkey.

His major research interests are in the use of artificial intelligence in education, adaptive and intelligent tutoring system, distance education software, e-learning and mathematics education.

Assist. Prof. Dr. Ozcan OZYURT

Karadeniz Technical University, OF Technology Faculty, Software Engineering Department,

Of, Trabzon, TURKEY

Phone: (0462) 3778389

Email: 00zyurt@ktu.edu.tr or oozyurt61@gmail.com 


\section{REFERENCES}

Allen, M.,Bourhis, J., Burrell, N. \& Mabry, E. (2002). Comparing student satisfaction with distance education to traditional classrooms in higher education: A meta-analysis. The American Journal of Distance Education, 16(2), 83-88.

Altun, A., \& Mazman, S. G. (2012). Programlamaya ilişkin öz-yeterlilik algısı ölçeğinin Türkçe formumun geçerlilik ve güvenirlik çalışması. Eğitimde ve Psikolojide Ölç̧me ve Değerlendirme Dergisi, 3(2), 297- 308

Anastasiadou, S. D., \& Karakos, A. S. (2011). The beliefs of electrical and computer engineering students' regarding computer programming. The International Journal of Technology, Knowledge and Society, 7(1), 37-51.

Askar, P., \& Davenport, D. (2009). An investigation of factors related to self-efficacy for java programming among engineering students. The Turkish Online Journal of Educational Technology, 8(1), Article 3.

Baser, M. (2013). Developing attitude scale toward computer programming. International Journal of Social Science, 6(6), 199-215.

Büyüköztürk, S. (2007). Sosyal bilimler için very analizi el kitabı, PegemA Yayıncılık.

Calli, L., Balcikanlı C., Calli, F., Cebeci, I. \&Seymen, F. (2013). Identifying factors that contribute to the satisfaction of students in e-learning. Turkish Online Journal of Distance Education-TOJDE, 14(1), 85-101.

Chang, S.L., Shieh, R.S., Liu, E.Z.F., \&. Yu, P.T. (2012). Factors influencing women's attitudes regarding computers in a computer literacy training program. The Turkish Online Journal of Educational Technology, 11(4), 177-187.

Demirtas, H., Cömert, M., \& Özer, N. (2011). Pre-service teachers' self-efficacy beliefs and attitudes regarding profession. Education and Science, 36(159), 96-111.

Hawi, N. (2010). Causal attributions of success and failure made by undergraduate students in an introductory-level computer programming course. Computers \& Education, 54(2010), 1127-1136.

Hongwarittorrn, N., \& Krairit, D. (2010). Effects of program visualization (jeliot3) on students' performance and attitudes regarding java programming. In The spring 8th International conference on Computing, Communication and Control Technologies, 6-9 April, Orlando, Florida USA.

Horzum, M. B., \& Çakır, Ö. (2009). The validity and reliability study of the Turkish version of the online technologies self-efficacy scale. Educational Sciences: Theory \& Practice, 9(3), 1343-1356.

Jegede, P. O. (2009). Predictors of java programming self efficacy among engineering students in a Nigerian University. International Journal of Computer Science and Information Security, 4(1\&2).

Korkmaz, 0. (2012). The Impact of critical thinking and logical-mathematical intelligence on algorithmic design skills. Journal of Educational Computing Research, 46(2), 173-193. 
Korkmaz, 0.,\& Altun, H. (2013). Engineering and ceit student's attitude regarding learning computer programming. The Journal of Academic Social Science Studies International Journal of Social Science, 6(2), 1169-1185.

Lau, W. W. F., \& Yuen, A. H. K. (2009). Exploring the effects of gender and learning styles on computer programming performance: implications for programming pedagogy. British Journal of Educational Technology, 40(6), 696-712.

Lenka, S. K., \& Kant, R. (2012). A study of attitude and perception of the learners regarding distance education in relation to their biographical factors. Turkish Online Journal of Distance Education-TOJDE, 13(4), 236-244.

McDowell, C., Werner, L., Bullock, H. E., \& Fernald, J. (2003). The impact of pair programming on student performance, perception and persistence. Paper presented at the 25th International Conference on Software Engineering, Portland, OR.

Nurazian M.D., Suzana B., Haslızatul F.M.H., \& Ismassabah I., (2007). Development of instruments for measuring learning attitudes regarding computer programming. In: National Conference on Programming Science (ATUR 07), 5 December 2007, Pacific KLIA, Selangor.

Ojo, D. O., \& Olakulehin, F.K. (2006). Attitudes and perceptions of students to open and distance learning in Nigeria. International Review of Research in Open \& Distance Learning, 7(1).

Ozyurt, H. (2014). Satisfaction clustering analysis of distance education computer programming students: A sample of Karadeniz Technical University. Turkish Online Journal of Distance Education-TOJDE, 15(2), 53-61.

Ozyurt, O. (2014). Clustering analysis of students' attitudes regarding distance education:Case of Karadeniz Technical University. Mevlana International Journal of Education (MIJE), 4(1), 113-122.

Pereira, H. B. D. B., Zebende, G. F., \& Moret, M.A. (2010). Learning computer programming: Implementing a fractal in a Turing Machine. Computers \& Education, 55(2), 767-776.

Robins, A., Rountree, J., \& Rountree, N.(2003). Learning and teaching programming: A review and discussion. Computer Science Education, 13(2), 137-172.

Şahin, I. (2007). Predicting student satisfaction in distance education and learning environments. Turkish Online Journal of Distance Education-TOJDE, 8(2), 113-119.

Stoilescu, D., \& Egodawatte, G. (2010). Gender differences in the use of computers, programming, and peer interactions in computer science classrooms. Computer Science Education, 20(4), 283-300.

Ural, 0. (2007). Attitudes of graduate students toward distance education, educational technologies and independent learning. Turkish Online Journal of Distance EducationTOJDE, 8(4), 34-43.

Yenilmez, K. (2008). Open primary education school students' opinions about mathematics television programmes. Turkish Online Journal of Distance Education, 9(4), 176-189. 